\title{
I ncreasing website use for provision of nursing contact hour programming
}

\author{
Jeanne Frentsos ${ }^{1}$, Cheryl Brilmyer ${ }^{2}$, Paula Garvey ${ }^{3}$ \\ 1. The Ohio State University Comprehensive Cancer Center - Arthur G. James Cancer Hospital and Richard Solove \\ Research Institute, Columbus, USA. 2. The Ohio State University, Columbus, USA. 3. The Ohio State University \\ Wexner Medical Center, Columbus, USA.
}

Correspondence: J eanne Frentsos. Address: The Ohio State University Comprehensive Cancer Center - Arthur G. James Cancer Hospital and Richard Solove Research Institute, Columbus, USA. Email: jeanne.frentsos@osumc.edu

Received: January 22, 2014

DOI : $10.5430 /$ jnep.v4n7p113

Online Published: May 5, 2014

Accepted: April 8, 2014

ep.v4n7p113

\section{Abstract}

There are continual changes in healthcare research, delivery, equipment and standards. These changes lead to the need for a focus on provision of nursing education to staff to assure safe delivery of quality patient care. However, cost factors, staffing limitations and availability of presenters are but a few factors that challenge the classroom delivery mechanism for nursing professional development. Use of nursing continuing education websites that can be individualized to meet the needs of each organization should be considered. This article reflects one academic Midwestern academic medical center's journey to establish a website for this use. Websites are now a familiar methodology among nurses and can overcome many hurdles in making quality, cost effective educational programs easily available while still meeting continuing education guidelines and organizational needs.

\section{Key words}

Nursing education, Websites, Continuing education, Professional development

\section{Introduction}

Lifelong learning is an important component of professional development, especially in nursing. Continual changes in medical research, revisions to nursing practice standards and new patient care therapies result in educational needs. In a rapidly changing health care environment, current and relevant continuing education is integral to maintaining a safe health care environment and highly competent work force ${ }^{[1,2]}$. As a result, health care organizations routinely offer educational programing to staff in order to provide this crucial information.

As applicable, every effort is made by organizations to offer contact hours to nurses attending these educational programs. Provision of contact hours is an important component in improving staff satisfaction, staff retention, easing staff's need to meet state licensure requirements and also assist in maintaining specialty nursing certification. Attendance and/or participation in continuing education can also be mandated by employers based on educational content or considered a criteria for advancement, such as with clinical ladder requirements. Continuing education is a motivator and benefit to practicing nurses ${ }^{[3]}$. 
Regretfully, educational programs which provide important content with expert presenters are happening across our country to rooms with many empty seats. Often the seats that are filled are not by the primary target audience. The nursing shortage and growing acuity level of patients in health care facilities are making it increasingly difficult for nurses to leave the bedside even for high priority educational content. Nurses report numerous barriers to participating in continuing education including program cost, time away from work, lack of funding and travel requirements ${ }^{[4]}$.

In nursing staff development, we must look at new methods of delivering educational content to meet the needs of our audience. Changes in generational learning patterns must be considered. The average college graduate has spent less than 5,000 hours in their lifetime reading but more than 10,000 hours playing video games and 20,000 hours watching $\mathrm{TV}^{[5]}$. Self-directed learners have been found to have a preference for teaching-learning experiences that incorporate the use of technology ${ }^{[6]}$.

Because health care organizations are primary sources of continuing education for their staff, more needs to be done to support nurses' professional development efforts and remove organizational barriers to participation ${ }^{[4]}$. Creative use of technology to ease accessibility to this information must be considered. Use of websites as an educational delivery methodology can assist in provision of this material in a manner in which nurses can access the content twenty four hours a day, seven days a week from work or home. Development of a continuing nursing education (CNE) website can also assure compliance with required components of the continuing education provider unit, provide certificates to users and maintain transcripts of completion for individual or unit recordkeeping. If the goal is to keep nurses at the bedside and not in a classroom, alternative educational models such as website use must be examined. Computer access is now available in many American homes, and is readily available on most nursing units, and the Web can provide relatively inexpensive instructional opportunities ${ }^{[3]}$.

\section{Our story}

As a member of a nursing professional development department and a CNE provider organization, there is a focus on providing the highest quality educational programming. Noting a gap in knowledge, we are driven to respond to nursing educational needs. Our Midwestern academic medical center has a plethora of national and regional experts in the field of nursing. However, not unlike those challenges experienced nationwide, we continue to struggle to provide access to these expert presentations for the nurses working in direct care positions. We questioned how education could be delivered to all staff with the hurdles of multiple shifts, various work locations, staffing needs in patient care areas and the challenge in scheduling of expert presenters. We also were aware of generational learning preferences, budgetary and other resource limitations. A high priority was to keep this delivery process as simple as possible for both the educator and the participant.

Through acknowledging these hurdles, a decision was made to assess how an increased use of technology could be operationalized to improve access to educational content. A team was established to note various technology sources, benefits and challenges. Key stakeholder input and support was generated. The support of nursing leadership in provision of resources needed for successful project implementation was crucial for success.

A team decision was made to focus on the development of a website that's sole focus was the provision of educational programs which offer nursing contact hours. The organization already had a learning management system (LMS) in place which assisted with other staff educational needs such as computer based learning modules, class scheduling, etc. However, this LMS did not provide ease in inclusion of internally produced programs and recordings which provided nursing contact hours. The need for provision of disclosure information, collection/collation of post activity evaluations and certificate distribution were but a few of the features the team desired in an online format.

The website development team (see Table 1) included those with expertise in nursing education principles, nursing continuing education providership requirements, information technology, video production, marketing, website support staff and nursing leadership. Over a period of 18 months, a CNE website was developed with the focused attention of all team members via bi-weekly meetings and firm assignment deadlines. The following characteristics were included in this 
website: homepage with search categories, required registration for first time users with password, options of viewing recorded programs or computer-based learning modules, required testing and/or participant evaluation per program, ability to print individualized program contact hour certificates for those meeting criteria for successful completion and a strong report generation feature for post activity evaluations.

Table 1. Website development team roles

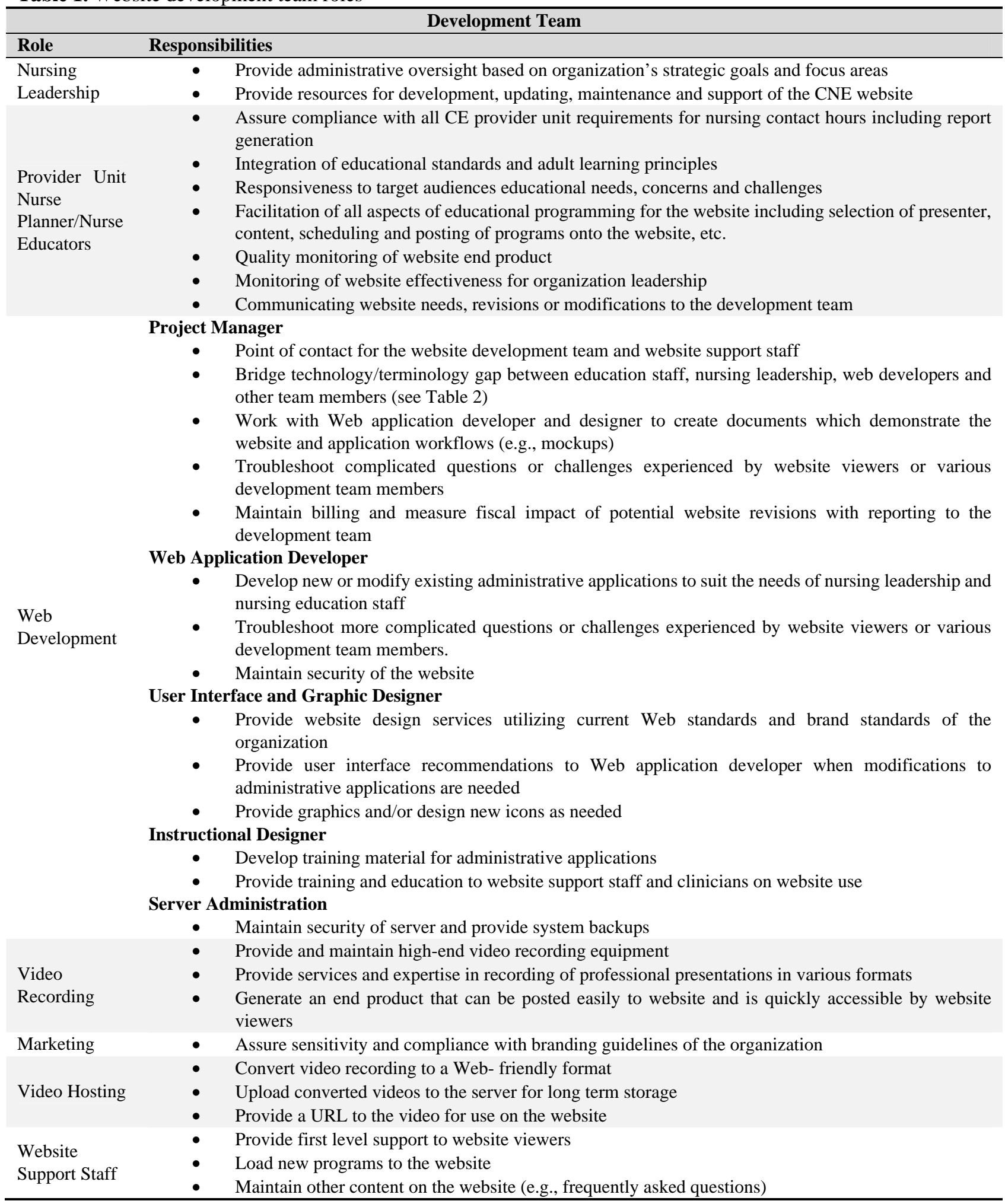


Table 2. Website terminology

\begin{tabular}{|c|c|}
\hline Term & Definition \\
\hline $\begin{array}{l}\text { Content Management } \\
\text { System (CMS) }\end{array}$ & $\begin{array}{l}\text { A Web-based application which allows for the adding and editing of information contained within a } \\
\text { website. The CMS leveraged for the CNE website allows for content entry into a WYSIWYG (what } \\
\text { you see is what you get) editor and therefore no programming knowledge is necessary for utilization. }\end{array}$ \\
\hline Hypertext Markup & HTML is a programming language that can be interpreted by a Web browser (e.g., Internet Explorer). \\
\hline Language (HTML) & Interpreted HTML code is displayed in a visual form, most often referred to as a Web page. \\
\hline $\begin{array}{l}\text { Cascading Style Sheet } \\
\text { (CSS) }\end{array}$ & $\begin{array}{l}\text { A cascading style sheet is a file which, when integrated into the HTML of the website, controls the } \\
\text { layout and text formatting of the website. Utilizing a CSS allows the website's designer to define styles } \\
\text { (font size, font color, etc.) globally for the entire website. It also separates the styling from the content, } \\
\text { which reduces the complexity of the HTML code. }\end{array}$ \\
\hline Image Optimization & $\begin{array}{l}\text { Optimizing images for the Web refers to resizing and/or compressing images prior to adding them to a } \\
\text { Web page. Image optimization allows for faster page load and image download times and most } \\
\text { importantly, a better user experience for the end-user. }\end{array}$ \\
\hline $\begin{array}{l}\text { Uniform Resource } \\
\text { Locator (URL) }\end{array}$ & $\begin{array}{l}\text { A URL is also known as a Web address and is a standard format utilized when a resource needs to be } \\
\text { referenced. In terms of Web content, a URL is utilized when an image is embedded into a page and } \\
\text { when a link needs to be created from one page to another or to direct individuals to a file (PDF, } \\
\text { PowerPoint, etc.) that is located on a server. }\end{array}$ \\
\hline Hyperlink or Link & $\begin{array}{l}\text { A hyperlink on a webpage is a word, string of words or image that, when clicked, takes the viewer to } \\
\text { another webpage or opens a document or other resource. Where the link takes the viewer, is determined } \\
\text { by the URL (see definition above). }\end{array}$ \\
\hline $\begin{array}{l}\text { Video Delivery: } \\
\text { Downloadable Format }\end{array}$ & $\begin{array}{l}\text { The complete video must be downloaded before viewing of the video can begin. Depending on the file } \\
\text { size and the end-user's Internet connection, this may create significant delays and a poor } \\
\text { user-experience. }\end{array}$ \\
\hline $\begin{array}{l}\text { Video Delivery: } \\
\text { Streaming Format }\end{array}$ & $\begin{array}{l}\text { Allows the end-user to begin watching a video while the remainder of the video downloads in the } \\
\text { background. The delay in watching the video is brief and occurs when the video is initially accessed. }\end{array}$ \\
\hline Media Player & $\begin{array}{l}\text { A media player is software that is downloaded and installed on a computer. Media players allow } \\
\text { individuals to play video and audio files within a range of supported file formats (e.g., wmv, mp4). }\end{array}$ \\
\hline Information Architecture & $\begin{array}{l}\text { Refers to how information is organized and labeled. Information, when referring to website } \\
\text { development, includes website navigation and the overall structure of content, as well as, database } \\
\text { design and software or application design. }\end{array}$ \\
\hline Hosting Service & $\begin{array}{l}\text { An establishment which provides dedicated server space for websites, website content and its } \\
\text { associated resources (e.g., images, videos). }\end{array}$ \\
\hline
\end{tabular}

Another aspect of the website that was of high importance to the development team was the need for ease of use. This was based on the knowledge that to achieve successful adoption of technology, users must believe the benefits of the technology outweigh the effort needed to use it ${ }^{[7]}$. Attention was paid to the overall appearance of the website and inclusion of branding for our healthcare organization. Use of text to be visually appealing, brief and accurate with correct grammar and absence of typing errors was addressed. Information was organized into sections to accommodate the skimming style of reading most viewers have when looking at websites. Whenever possible, hyperlinks were included that provided additional layered information to not overwhelm the viewer with too much content on one screen. Additional website links were included to take viewers to the state board of nursing, various nursing certification specialty websites and other online resources of nursing interest. Not only was accuracy in content closely evaluated but presence of omissions was noted as well. To enhance satisfaction and support of professional development, it was prioritized that there would be no charge for our organization's staff in utilizing this website.

Following the posting of an internally produced sample program onto the website, pilot testing was implemented to assure usability met the development team's expectations. A select target audience well versed in nursing education principles as well as additional staff nurses who were novices in the use of educational websites was involved. Revisions were made based on the feedback provided by this audience. 
Educational content provision via recorded programs for the website was then undertaken. Each individual program was pilot tested and evaluated to assure it met nursing continuing education criteria as an independent study offering. The listing of available recordings continues to grow over time with recordings set up to automatically archive on a specific date unless staff re-enter the recording into the system. This assures that no website content remains posted beyond that time period without careful review to assure content accuracy and continuing education providership compliance. Methods of recording and saving presentations to servers for ease in viewer playback have been an important component of this website's success.

Coaching of presenters for the recordings was also implemented with provision of applicable PowerPoint templates for a standardized appearance. These presenter interactions helped improve their understanding of methods for handling questions which may occur from a live audience and increased their appreciation of how educational content, delivery methods and demeanor may need to be adjusted to better fit a recorded presentation. Through use of recorded programs that offered the option of PowerPoint with voiceover, which did not include a presenter screen shot, an expansion of our presenter base was discovered. Staff that was not comfortable presenting to live audiences liked the idea the presentation could be easily edited to meet expectations of their final programming outcome. This increased the number of presenters available and ultimately increased our program inventory. This has also been a wonderful way to develop experienced nurses who are novice presenters.

Marketing of the CNE website was undertaken in a variety of ways. Flyers, posters, emails, ads in nursing newsletters, staff awareness campaigns and PowerPoint programs introducing use of the website were developed and implemented. Content relaying the CNE website benefits and steps to access were added to nursing orientation. Computers, along with staff to assist nurses in website registration, were made available at staff meetings, mandatory education programs, nursing grand rounds and other special nursing events. Links to the website were placed on the hospital's main Web portal. As the website matured, staff have been given mandatory viewing assignments based on their unit assignment and responsibilities. Use of presenters from within our organization has also been found to generate increased interest from staff and link them with local experts in a specific clinical content area.

The CNE website quickly grew as a popular method by nursing staff to receive educational content and as a result, became a frequently utilized tool for education distribution (see Figure 1 and 2). Staff liked to receive the content at a time and place that met their schedule and also appreciated the ability to watch the information repeatedly, if needed. The ease in having immediate, printable access to their individualized contact hour certificate remains a popular feature. Years in which state nursing re-licensure is required does appear to drive an increased number of staff to use of the website.

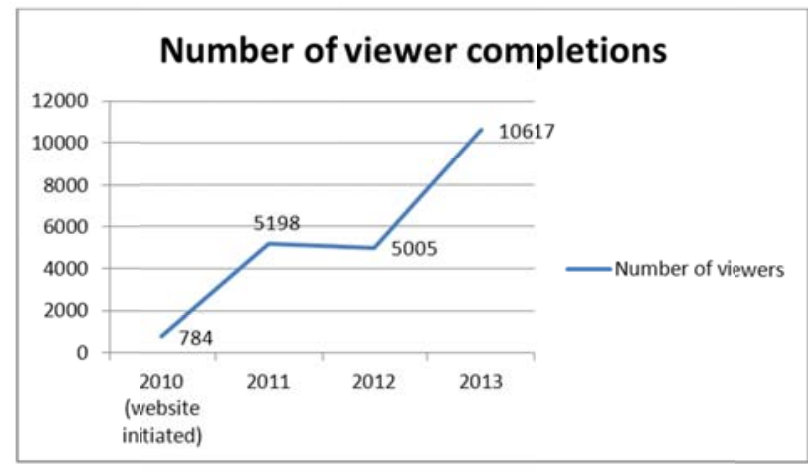

Figure 1. Website growth per number of viewer completions of programs

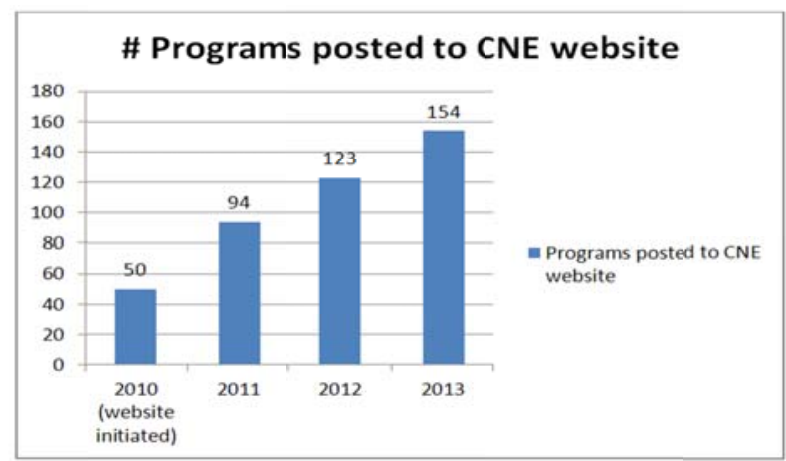

Figure 2. Website growth per number of educational programs available

The website continues to evolve based on ongoing feedback generated from staff surveys, evaluation responses and various communications. With continual change in computer hardware, programming languages, website capabilities, 
educational content and many other factors, there is a need to have focused oversight of the website. The need to assure quick download for the video recordings as well as the viewer's ability to move quickly between screens and connections with other websites has been a prime component of satisfaction. Inclusion of a "Frequently Asked Questions" page on the website that addresses the technical requirements of the website, including download links to various media players, has also been helpful. To further assist with supporting viewers, there is a password recovery feature and an automated process for re-activating an account on the website. Of importance is the presence of an email contact form for viewers to ask questions about educational content or website usage.

\section{Benefits of website}

\subsection{Benefit: CE compliance}

The website is beneficial in aiding compliance to continuing education guidelines for independent study programming. During development of the website, the organization's development team followed the American Nurses Association Commission on Accreditation, Ohio Board of Nursing, and the Ohio Nurses' Association's Continuing Education guidelines. Each educational program has a disclosure page that contains all required content. Each page of the website carries our provider statement. One of the duties of a continuing education nurse planner is to complete post activity evaluation reports. The website automatically calculates the participant's evaluation responses that details the achievement of each objective and the program's overall purpose, and calculates the total number of minutes that it took each participant to complete the program. This function takes some workload off the nurse planner. The website maintains these records so that the nurse planner can access them at any time.

Nurse planners decide the criteria for successful completion for their programs; these criteria can include pre and post-tests. The CNE website has the ability to load pre and post-tests for participants to complete. Tests can be set up as multiple choice or true/false for grading purposes. The nurse planner can mandate the order of activities such as to first view the program, then complete the post-test, and finally complete the evaluation form. The site locks down the certificate until the participant completes all requirements. The website grades the tests and gives immediate feedback to the participant. The website tracks and maintains records of usage, such as how many times it took the participant to pass the test and which questions were missed most frequently. This functionality can reflect issues with problematic questions and can reveal content that is not easily understood by the participants and thus needs more explanation. Testing also provides enhanced content evaluation for educational programming. The nurse planner can load supplemental printable handouts for each program. Linkages to applicable policies and/or other helpful websites can also be provided.

\subsection{Benefit: Educational impact and assignments}

Educational principles note the benefit of adult learners having control in their learning environment. Adults learn best in an active setting. Traditional, classroom-based, didactic educational sessions tend to be passive for the learner and do not promote autonomy in learning. Conversely, online learning promotes autonomy and control. "Benefits of online learning include deeper learning; increased interaction; increased sense of learner control; economic efficiency; easily updated learning materials; and improved learner satisfaction, retention, and learning outcomes” ${ }^{[8]}$. Nurses can now view educational programs at their leisure without impacting unit productivity or patient safety.

Recorded programs on the website can be assigned to staff for a variety of purposes. For example, staff can be assigned a program as part of their initial orientation, in response to changes in healthcare regulatory standards, new technologies or quality issues. These online programs can be used in situations in which a nurse is transferred from one unit or patient population to another within their professional practice. Nurses tend to develop highly specialized skills in their practice setting. When a nurse transfers from one hospital unit to another or changes health care settings altogether, there most likely will be a need for continuing education that focuses on specific prevalent practice issues ${ }^{[3]}$. Viewing of programs online permits a new or transferring nurse to therefore have more orientation time spent on the new unit or department 
versus in the classroom. As the CNE website has grown in popularity throughout the organization it is now inclusive of mandatory educational programs based on a specific nurse’s service line or responsibilities.

\subsection{Benefit: Reporting features}

The website's reporting features are a wonderful asset. The website tracks the number of programs viewed, which programs were viewed most frequently, the overall usage of the website, and the number of users from each business unit in the hospital system. Initially, this functionality assisted the development team with knowing which areas of the hospital needed more information on the website to increase usage. This functionality also assists with knowing which programs and subject matter are the most popular in order to meet viewer's learning needs. Reporting of staff usage has also assisted nursing leadership in understanding the positive impact of this as an educational delivery method.

Participants, nurse educators and nursing leadership all benefit from the reporting functionality. The website maintains transcripts for participants to view at any time. The participants can show the transcript to nurse managers to verify completion of mandatory activities or can use them to track licensure or certification requirements.

\subsection{Benefit: Cost and staffing impact reduction}

Educational programming can be costly in both human and financial resources. In today's healthcare environment of higher nurse-to-patient ratios and higher patient acuity, getting staff off the unit to attend classes is increasingly difficult. Use of online learning reduces cost for program attendance and decreased impact on unit staffing. If one factors together an average salary for a nurse of $\$ 35 /$ hour, a two-hour continuing education program, and an audience of 20 nurses, the total cost of that program in human resources alone is $\$ 1,400$. Then one must factor in the cost of a presenter, possible room charges, travel time and lodging, and extra nurses on the floor to cover for those attending the class. Repeating of a program to be able to access additional nurses from various shifts or work locations subsequently causes these prices to quickly escalate. When nursing staff attend a continuing education program, management must frequently find other nurses to cover the unit. Often, these nurses may be on overtime. If a typical overtime salary is 1.5 times the hourly salary at $\$ 35 /$ hour, management must pay $\$ 52.50 /$ hour per covering nurse. In many organizations, continuing education is provided free to nursing staff; thus, the cost above is transferred to the home unit or education department.

Using Web-based education, the cost is typically limited to the one-time cost of the presenter and the cost of recording the program. Costs for room charges, audience attendance, repeated access to the presenter and covering staff on the patient care unit are eliminated. This example would equate to a cost of $\$ 160$ per two-hour Web-based program, which provides a potential for a broad nursing viewer base, compared to over $\$ 1400$ for a classroom-based program impacting approximately 20 nurses.

Currently the number of qualified nurse faculty and nurse researchers is well below the national need ${ }^{[3]}$. The access to presenters able to provide multiple repeat live educational offerings is therefore very challenging. In a live delivery teaching methodology, repeated access is required in order to impact a large learner population. Use of Web-based recorded programming is extremely helpful in its ability to afford scheduling of recordings at a time convenient for the presenter, as well as the learner. The ease in ability to increase impact of expert presenters is a hidden benefit of website use.

\section{Resources needed for website development}

\subsection{Financial}

There are financial considerations to think about and plan for when embarking on development of a CNE website. The financial considerations include initial cost of development, regular maintenance and hosting fees. Additional costs include enhancements to the website and its associated applications as business processes and technology change. 
The initial investment in development of the website is perhaps the most significant. This should be expected because the shell in which the programming will be administered needs to be created and the associated workflows implemented. Even though it is the most significant investment made, there are ways to reduce development costs or at least ensure re-development does not take place before or shortly after launch.

The way in which the development team (see Table 1) did this was by meeting regularly and planning meticulously before any programming of the website began. The responsibilities of the development team and requirements of the website were verbally communicated during the bi-weekly meetings. Screen mockups were then provided back to the development team and reviewed as a group. Any questions or concerns regarding layout, functionality or workflow were addressed during the bi-weekly meetings. Mockups were updated with any changes necessary. Development of the website utilizing mockups and required documents ensured all members of the development team were on the same page in regards to the functionality and workflow of the website. It also helped reduce cost by defining the scope of the project and limited the likelihood that functionality would be added or revised after development began.

An additional consideration which has a financial impact is how frequently the website will need to be redesigned or enhanced. As part of a larger organization, it is a requirement to adhere to the branding guidelines of the organization and these guidelines may change during the lifespan of the website. It is also likely that technology will change. It is important to budget annually to make technological enhancements to the website to meet the needs of the user base and stay current in the marketplace.

\subsection{Website \& Technology literacy}

Due to the many layers and complexity of a CNE website, it is important that all members of the development team have the technical expertise and vocabulary to be able to communicate their needs and report issues. As mentioned previously, technical concepts were discussed during the bi-weekly meetings. From these discussions improved understanding was acquired by team members through the creation of screen mockups, which provided a visual representation of more technical concepts.

As much as possible, development of the CNE website and training on the support applications was conducted in stages. Programming in this way allowed the development team to review current website progress while another set of functionality was being developed. This approach kept the project moving in order to meet deadlines, but it also gave the development team portions of a complex application to review rather than the entirety of the application all at once, reducing information overload.

Training was conducted in a similar manner, over three separate sessions. The training sessions were conducted with those who were identified as the CNE support staff and with the provider unit nurse planners. Through training and use of specific applications, these individuals gained a deeper understanding of the website including technical concepts and terminology while improving administrative skill sets. Some of the more technical terms utilized over the course of development and maintenance of the website have been provided (see Table 2).

\subsection{End user support}

End-user support for the CNE website is accomplished using a tiered approach. Website user support requests are funneled through the CNE staff. These individuals have been trained on the business process and workflow of the website and can respond to basic requests from end-users who are having difficulty logging in or accessing programs on the website. Any requests for assistance that cannot be answered by the CNE staff, or that are more technical in nature, are forwarded to the appropriate member of the Web development team.

\section{I mplications of website use/ moving forward}

Copyright considerations should be taken into account when evaluating and uploading website content. Posting presentations previously offered to live audiences or recorded specifically for the website must be reviewed for possible 
copyright issues. A Fair Use analysis is necessary when considering whether to include any third party copyrighted content in any posted presentations ${ }^{[9,10]}$. It may be necessary to remove or request permission to use third party content. Website workflow steps should also include submission of required release forms signed by presenters, possible inclusion of disclaimer statements on the website itself, and an end user copyright compliance agreement provided during the registration and login process. Continuing education program coordinators and website managers are encouraged to seek copyright information ${ }^{[11,12]}$ and advice from their institutional copyright or legal affairs departments.

Lessons have been learned as we have grown more experienced in CNE website management. Although this was determined to be a very cost effective method for delivering educational content, we did implement even further cost containment measures to decrease ongoing cost per registered participant. We established a required "reactivation" process for website viewers who had not visited the site over a prolonged period of weeks which resulted in a positive fiscal impact. Need for staff resources to maintain oversight of response to emails, updating website content, loading of new programs and assuring website quality standards are maintained have been confirmed.

Future opportunities for the CNE website include consideration of an expanded viewer audience, potential revenue generation, inclusion of conference registration and addition of new educational software applications. Programming that permits presenters to record from their personal computers and perform their own editing is also possible. The ability of the website to adapt to the needs of the organization and its end users is an important benefit.

Opportunities can be created for faculty and various departments to learn together to provide the best services possible, highlight and address organizational issues that may impact success, and create an atmosphere that empowers teams while offering rewards for collaborative efforts ${ }^{[13]}$. The need for multidisciplinary teams to be able to understand each other's professional language, become knowledgeable of project guidelines and requirements and therefore optimize technology to meet educational project goals is continual. Positive team dynamics, communication and ongoing support to maintain quality of the website is instrumental.

Website use is an underutilized educational delivery methodology that can be added to most nursing education department's toolboxes. Through use of recording live presentations, access to content can be expanded beyond the classroom to numerous other participants. Websites can be established that meet the continuing education standards for independent study programming while offering heightened levels of program evaluation and improved satisfaction for learners, presenters and nursing leadership.

As nursing continues to change and grow as a profession and as a discipline, so must the manner in which we prepare our nurses for today's healthcare challenges. The integration and utilization of technology within the educational classroom, as well as the home environment, has become widely available and accessible ${ }^{[13]}$. McSherry and Warr ${ }^{[14,15]}$ suggest that excellence in nursing care is about meeting the challenges posed by professional, societal, political and economic demands in a proactive, not reactive way.

Nursing recognizes that technological advances are dramatically increasing opportunities to improve the quality of and access to nursing education ${ }^{[3]}$. However, use of technology should not be limited to the nursing academic world but be expanded for inclusion for clinical based nursing staff development. With reduced education department budgets, increased workload, and increased need for responsiveness to change in a volatile health care environment we must use all resources available to focus on provision of accessible, high quality educational programming. Not only does use of websites prove advantageous to the nurse, it is also of benefit to the educational department by maximizing educator time, accessibility and impact.

\section{References}

[1] Levett-Jones T. Continuing education for nurses: necessity or nicety? The Journal of Continuing Education in Nursing. 2005; 36(5): 229-233. PMid:16218012

Published by Sciedu Press 
[2] Penz K, D’Arcy C, Stewart N, Kosteniuk J, Morgan D \& Smith B. Barriers to participation in continuing education activities among rural and remote nurses. The Journal of Continuing Education in Nursing. 2007; 38 (2): 58-66. PMid:17402377

[3] Sanford J, Townsend-Rocchiccioli J, Trimm D \& Jabobs M. The web quest: constructing creative learning. The Journal of Continuing Education in Nursing. 2010; 41(10): 473-479. PMid:20506929 http://dx.doi.org/10.3928/00220124-20100503-04

[4] Nalle M, Wyatt T \& Myers C. Continuing education needs of nurses in a voluntary continuing nursing education state. The Journal of Continuing Education in Nursing. 2010; 41(3): 107-115. PMid:20229960 http://dx.doi.org/10.3928/00220124-20100224-03

[5] Prensky M. Digital natives, digital immigrants. On the Horizon. 2001; 9(5): 1-6. http://dx.doi.org/10.1108/10748120110424816

[6] Boyd C. Mock webpage: An innovative assignment for second degree nursing students. Nursing Forum. 2010; 45(3): $159-165$. PMid:20690991 http://dx.doi.org/10.1111/j.1744-6198.2010.00184.x

[7] Welsh S \& Houston S. Development and evaluation of a nursing portal. The Journal of Continuing Education in Nursing. 2010; 41(3): 133-138. PMid:20229964 http://dx.doi.org/10.3928/00220124-20100224-02

[8] Altimier, L. Benefits of a flexible neonatal online nursing orientation program. Newborn and Infant Nursing Reviews. 2009; 9(2): 83-87. http://dx.doi.org/10.1053/j.nainr.2009.03.014

[9] The Ohio State University Health Sciences Library. http://hsl.osu.edu/copyright/fair-use-checklist

[10] Stanford University Libraries. http://fairuse.stanford.edu/

[11] United States Copyright Office. http://www.copyright.gov/

[12] Columbia University Libraries. http://copyright.columbia.edu/copyright/

[13] Steinert Y. Learning together to teach together: interprofessional education and faculty development. Journal of Interprofessional Care. 2005; 19: 60-75. PMid:16096146 http://dx.doi.org/10.1080/13561820500081778

[14] Jones D \& Wolf D. Shaping the future of nursing education today using distant education and technology. ABNF Journal. 2010 Spring; 44-47. PMid:20533754

[15] McSherry R \& Warr J. An introduction to excellence in practice development in health and social care. Open University Press 2008, Maidenhead.

[16] McSherry R \& Warr J. Implementing excellence in your health care organization: managing, leading and collaborating. Open University Press 2010, Maidenhead. 